\title{
LOS CAMINOS DE BOURDIEU EN ARGENTINA: ÚLTIMAS NOTICIAS
}

\section{BOURDIEU'S PATHS IN ARGENTINA: LATEST NEWS}

\author{
Denis Baranger*
}

\section{Introducción}

Abordaré aquí la recepción argentina de Bourdieu poniendo el foco en la etapa abierta a partir de su muerte ${ }^{2}$. Contrariamente a lo acaecido en Brasil donde desde el principio se impuso un uso productivo de la obra de Bourdieu, poniendo a trabajar sus conceptos (en especial con los antropólogos del Museo Nacional de Rio), en Argentina predominó al inicio un estilo de recepción fuertemente teoricista, y hubo que esperar los 90 para que se consolidaran con mayor fuerza las modalidades de recepción más productivas que continúan caracterizando a la etapa actual (BARANGER, 2008; 2013).
En lo que sigue, comenzaré realizando una breve presentación de las condiciones que llevaron a que las ciencias sociales argentinas se desarrollaran en general con gran ímpetu en el nuevo siglo, convirtiéndose en un terreno propicio para el florecimiento de trabajos de investigación de inspiración bourdieusiana. Luego, abordaré las trayectorias de un conjunto de exponentes de esta tradición, con el propósito de mostrar los diferentes caminos que han podido emprender en los últimos años. Finalmente, concluiré discutiendo acerca del no-campo de las ciencias sociales en Argentina, y sobre el lugar del bourdieusianismo en ese espacio.

* Docente do Programa de Pós-Graduação em Antropología Social, Universidad Nacional de Misiones UNaM - (Misiones/AR). E-mail: baranger.denis@gmail.com

1. Trabajo elaborado en el marco del proyecto $16 \mathrm{H} 437$. Agradezco las observaciones de dos comentaristas anónimos que me permitieron mejorar sustancialmente este texto. Los errores que puedan subsistir son de mi exclusiva responsabilidad.

2. A. T. Martínez (2007) abordó la recepción argentina de Bourdieu, pero no abarca el período que trataremos aquí. 
1. La expansión de las ciencias sociales argentinas en los inicios del nuevo siglo

La llegada del siglo XXI encontró a la Argentina en un estado terminal, transitando por una crisis económica, social y política de dimensiones cuasi trágicas. El obligado cambio de rumbo de la política económica, luego del tendal dejado por los fundamentalistas del mercado, unido al inicio de un ciclo históricamente excepcional de alza de precios de las commodities, crearon las condiciones para una rápida recuperación económica y, dentro de este contexto, para una expansión sin precedentes de las ciencias sociales.

Las reformas llevadas a cabo durante la década del 1990 por el Presidente Menem, en cuyo corazón se encontraba la privatización a mansalva de los servicios públicos y de las empresas estatales, tuvieron resultados funestos en muchos casos. Pero el programa no avanzó al mismo ritmo en todos los sectores. Así, en lo que hace a la enseñanza universitaria no hubo ni provincialización ni privatización del servicio, y en lo fundamental las universidades públicas continuaron siendo nacionales, de acceso libre y gratuito, y autónomas en su gobierno. En este ámbito, el impetu reformista se limitó a impulsar la creación de media docena de nuevas universidades en el conurbano bonaerense ${ }^{3}$, poniéndolas en competencia con la Universidad de Buenos Aires (UBA) (visualizada como un bastión opositor), y a propiciar un sistema de estímulos, al compás de los organismos internacionales, tendiente a la institucionalización de la investigación en las universidades y a fomentar el desarrollo de las carreras de maestría y de doctorado. En 1994 se puso en marcha una política de desarrollo de los estudios de postgrado, con vistas a que en un plazo de diez años todos los profesores universitarios se encontraran doctorados. Aunque el objetivo era imposible de ser cumplido en el plazo original, pero dio lugar a una política de Estado de hecho que aún subsiste, transcurrido un cuarto de siglo.

Los gobiernos de Néstor y de Cristina Kirchner potenciaron estos procesos, y en especial colocaron en el centro de su agenda la política de ciencia y tecnología, lo que se tradujo en la creación del Ministerio de Ciencia y Tecnología en 2007 y en un aumento espectacular del presupuesto asignado a las universidades y a la ciencia, asegurando a la vez un incremento en los montos de los sueldos y becas y un aumento de las plazas. El número de investigadores aumentó un 77\%, pasando de 21.743 (en equivalentes a jornada completa) en 2003 a 38.497 en 2015. Para los becarios, el crecimiento fue aún mayor (157\%). alcanzándose en 2015 el número de 14.473 (MINCYT, s.f.).

\subsection{Las instituciones: el Conicet y las uni- versidades}

Para describir el espacio de las ciencias sociales considero fundamental tomar en cuenta en primer lugar las principales instituciones de enseñanza y formación superior.

El Consejo Nacional de Investigaciones Científicas y Técnica (Conicet) ${ }^{4}$ ha sido el ámbito principal para el crecimiento de

3. Las universidades nacionales de General Sarmiento (UNGS), Lanús (Unla), Lomas de Zamora (UNLZ), Quilmes (Unqui), San Martín (Unsam), y Tres de febrero (Untref).

4. El Conicet - creado en 1958 sobre el modelo del CNRS francés - es el principal organismo dedicado a la promoción de la ciencia y la tecnología en la Argentina. 
recursos humanos descripto, aumentando tanto el otorgamiento de becas, como el número de ingresos a la Carrera de Investigador Científico (CIC). De este modo la investigación pasó a ser percibida como una inserción laboral deseable y factible de ser realizada para muchos egresados de ciencias sociales $^{5}$. En la actualidad el Conicet cuenta con diez mil investigadores en la CIC, y once mil becarios doctorales y postdoctorales.

Las universidades nacionales son el otro ámbito institucional crucial para el desarrollo de la investigación, mediante la producción de recursos humanos calificados y como ámbito de su inserción laboral. En la UBA son especialmente relevantes la Facultad de Filosofía y Letras (FFyL) y la de Ciencias Sociales (FCS). La primera de ellas, creada en 1896, abarca once departamentos:
Antropología, Historia, Educación, Letras y Artes, entre otros. La segunda fue fundada en 1988 - reagrupando las carreras de grado en Sociología, Ciencia Política, Comunicación Social, Trabajo Social y Relaciones de trabajo -, y recién creó su programa de doctorado en 1996. Ambas facultades expandieron fuertemente su producción de doctores $^{6}$ a favor del crecimiento del número de becas otorgadas por el Conicet.

Aunque algunas de las universidades del conurbano creadas en los 90 han venido creciendo en importancia en los últimos años, la UBA continúa siendo por lejos la principal fuente de científicos sociales. La Tabla 1 muestra el origen de las titulaciones de 1871 investigadores de todas las disciplinas sociales y humanas de la CIC activos en 2013.

Tabla 1 - Investigadores de la Carrera de Investigador Científico (CIC) del Consejo Nacional de Investigaciones Científicas y Técnica (Conicet) según universidades de obtención de su grado y doctorado (2013).

\begin{tabular}{lllll} 
Universidades & \multicolumn{2}{c}{ Grado } & \multicolumn{2}{c}{ Doctorado } \\
UBA & \multicolumn{1}{c}{$\mathrm{f}$} & $\%$ & $\mathrm{f}$ & $\%$ \\
La Plata & 888 & $47 \%$ & 607 & $32 \%$ \\
Córdoba & 193 & $10 \%$ & 178 & $10 \%$ \\
Otras UUNN & 121 & $6 \%$ & 102 & $5 \%$ \\
Religiosas & 460 & $25 \%$ & 277 & $15 \%$ \\
Privadas no religiosas & 121 & $6 \%$ & 60 & $3 \%$ \\
Extranjeras & 36 & $2 \%$ & 34 & $2 \%$ \\
Extranjeras \& UBA & 0 & $0 \%$ & 29 & $2 \%$ \\
Sin título & 10 & $1 \%$ & 94 & $5 \%$ \\
Sin dato & 5 & $0 \%$ & 0 & $0 \%$ \\
TOTAL & 1871 & $100 \%$ & 1871 & $100 \%$ \\
\hline
\end{tabular}

UBA: Universidad de Buenos Aires; UUNN: otras universidades nacionales.

Fuente: elaboración propia sobre datos de la CIC.

5. Las becas doctorales se otorgan con una duración de cinco años para realizar un doctorado en una universidad argentina. Luego, se puede aspirar a una beca postdoctoral (por uno o dos años), y al ingreso a la CIC con un cargo estable full-time.

6. De 2010 a 2017 la FCS produjo 647 nuevos doctores, y la FFyL 861. 
En la UBA se han graduado un $47 \%$ de ellos. En cambio, en el doctorado, si bien se mantiene la primacía de la UBA, aparecen con un peso fuerte las universidades extranjeras". La categoría "Extranjeras \& UBA" se refiere a 29 tesis con doble titulación, realizadas en cotutela entre la UBA (en la FCS y la FFyL) y universidades francesas, a partir de 2004. De modo que se puede afirmar que la UBA da cuenta de un 34\% de los doctorados, y también que en las universidades extranjeras se doctoró un 28\%.

En la Tabla 2 se discrimina por país a los 519 investigadores de la CIC doctorados en el extranjero.

Tabla 2 - Investigadores de la Carrera de Investigador Científico (CIC) según país extranjero en el que se doctoraron (2013) ${ }^{8}$.

$\begin{array}{lll}\text { Países } & f & \% \\ \text { Francia } & 120 & 23 \% \\ \text { España } & 111 & 21 \% \\ \text { Inglaterra } & 44 & 8 \% \\ \text { Otros europeos } & 69 & 13 \% \\ \text { Brasil } & 40 & 8 \% \\ \text { Otros América Latina } & 33 & 6 \% \\ \text { EEUU (y Canadá: 3) } & 102 & 20 \% \\ \text { TOTAL } & 519 & 100 \%\end{array}$

Fuente: elaboración propia sobre datos de la CIC.

Francia ha sido el destino principal para doctorarse en el extranjero entre los investigadores del Conicet. Concentra un 23\% (incluyendo el 2\% con "tesis dobles).

Finalmente, en la UBA fue creado en 1996 el Centro Franco Argentino de Altos Estudios (CFA), con el objetivo de fomentar la cooperación científica y universitaria en el ámbito de las ciencias sociales y humanidades. Desde su inicio, ha contado con el apoyo intelectual, institucional y financiero de la École des Hautes Études en Sciences Sociales (EHESS) de París, en la realización de seminarios de postgrado así como de conferencias dirigidas a un público amplio.

Con la dirección por la parte francesa a cargo sucesivamente del antropólogo Gilles Rivière, del filósofo Patrice Vermeren, y actualmente de Guillaume Boccara, antropólogo del Centre de Recherches sur les Mondes Américains (CERMA), el CFA ha permitido el contacto directo con investigadores franceses provenientes de la EHESS $\mathrm{y}$, no excluyentemente, vinculados al pensamiento de Bourdieu'. Los estudiantes de postgrado argentinos tienen la oportunidad de cursar, y eventualmente revalidar, seminarios para su doctorado.

7. Entre los investigadores más antiguos tienen mayor peso las modalidades "Extranjeras" y "Sin título". En los jóvenes predominan los doctorados en universidades nacionales.

8. 29 tesis "dobles" asignadas a Francia; EEUU: Estados Unidos.

9. En un artículo en Chile el mismo Boccara (2012) hace gran uso de Bourdieu. 


\subsection{Las publicaciones: revistas y editoriales}

El otro elemento clave en la conformación del espacio de las ciencias sociales son las publicaciones científicas. En cuanto a las revistas, aunque es importante la cantidad de publicaciones de artículos por argentinos en revistas extranjeras de habla hispana, en los últimos años ha aumentado mucho en ciencias sociales el número de revistas publicadas en el país. Este es en parte un efecto de las presiones para una mayor producción de artículos por parte del Conicet y, en menor grado, de las universidades nacionales.

De acuerdo a un relevamiento de la situación en 2015 (SALATINO, 2018, p. 257), había en Argentina 850 revistas activas en el área de las ciencias sociales y humanidades (3.609 en Brasil). Muchas de estas revistas, empero, tienen una circulación reducida, que no se extiende más allá de la institución donde se las produce.

La revista decana, Desarrollo económico, fue concebida desde su inicio en 1961 como multidisciplinar, incluyendo colaboraciones de economistas, sociólogos, politólogos, historiadores y antropólogos y goza de un amplio prestigio. Pero otras publicaciones son más relevantes en lo que hace a Bourdieu, como es el caso, por ejemplo, de Apuntes de investigación, Cuestiones de sociología, El taco en la brea, Prismas, Papeles de trabajo o Trabajo y sociedad.

En las ciencias sociales, el libro es un vehículo de gran importancia (CLEMENS et al., 1995), por lo cual hay que considerar también el mercado editor. La Argentina ha sido tradicionalmente sede de una intensa actividad editorial, y una de las principales plazas de producción del libro hispano, junto con España y México. Al compás de los ciclos que signaron la evolución del tipo de cambio de la moneda nacional, el libro impreso en Argentina ha tenido como destinatario el mercado interno, pero también, durante períodos extensos, la exportación hacia Iberoamérica.

Aunque no se dispone de ningún estudio sobre el capital simbólico de las editoriales que publican libros de ciencias sociales, Siglo XXI Argentina suele ser reconocida como una de las más prestigiosas. Contrariamente a lo que sucede con la mayor parte de las editoriales, Siglo XXI Argentina no demanda aportes al autor para cubrir los costos de edición, y no imprime nunca menos de 3.000 ejemplares. De acuerdo a su Director, Carlos Díaz (2018), egresado de Sociología de la UBA y a su vez hijo de un famoso editor, Bourdieu no es un bestseller. Si se piensa en el trabajo de traducción y edición implicado por las 569 páginas de La nobleza de Estado (BOURDIEU, 2013b), se comprende que los 3.300 ejemplares vendidos hasta el presente en todo el mercado de América Latina, no son exactamente un gran negocio ${ }^{10}$. Sin embargo, considerada como longseller, y como una fuente de prestigio, su publicación adquiere mayor sentido. Razón por la cual ha venido ampliando el lugar de Bourdieu en su catálogo, reeditando obras abandonadas por otras casas editoras. En el mercado de las traducciones de Bourdieu, Siglo XXI Argentina ha quedado en una situación de competencia con Anagrama: luego de haber pujado sin éxito por los derechos de pu-

10. En Argentina las traducciones al español de Bourdieu y otros autores se han beneficiado con diversos subsidios del Estado francés (SORÁ e DUJOVNE, 2018, p. 284-285). 
blicación del curso Sur l'État en el Collège de France, logró obtener los de Sociologie Générale (2019).

Hay también otras editoriales que, operando en una escala más reducida, a veces próxima a lo artesanal, son muy significativas. Algunas son sellos independientes (e.g., Antropofagia, Biblos, Manantial, Prometeo, Nueva Visión); otras son universitarias, como Eudeba, o las editoriales de Cuyo, Quilmes y Villa María.

\section{Trayectorias académicas y apropiaciones de Bourdieu}

No es mi objetivo ocuparme aquí de todos los integrantes, ni de los más importantes, del bourdieusianismo argentino, una construcción cuyas fronteras son inherentemente borrosas ${ }^{11}$. Tratándose de un universo demasiado numeroso como para indagarlo en su totalidad, seleccioné un conjunto de casos que considero representativos del mismo, sin ninguna pretensión de exhaustividad.

Comenzaré presentando a investigadores más jóvenes, formados en el país y en Francia, pasando luego a otros más maduros, para finalizar con aquellos que han constituido equipos en el país, dando lugar al desarrollo de programas sostenidos en el tiempo de investigaciones empíricas tributarias de las ideas teóricas y metodológicas de Bourdieu.

\subsection{Jóvenes bourdieusianos "por la libre"}

Juan Dukuen y Emiliano Gambarotta jamás pisaron las instalaciones del Centre de Sociologie Européenne (CSE) en París. Se apropiaron de la obra de Bourdieu por sus propios medios, sin inscribirse en ningún tipo de proyecto colectivo con ese propósito. No se conocen el uno al otro, aunque revistan ambos en la categoría de Investigador Asistente, el escalón inicial de la CIC del Conicet. Sus trayectorias ilustran la potencialidad del medio argentino para producir obras de valor en un modo puramente endógeno.

Juan Dukuen, nacido en 1983, es el más joven. Sus bisabuelos fueron alemanes del Volga, llegaron a la Argentina para instalarse como agricultores en la zona de Coronel Suárez. Su madre fue maestra y se jubiló como directora de escuela, en tanto que su padre, un autodidacta que no fue más allá del séptimo grado, ejerció los oficios más variados, incluyendo el de periodista.

Respondiendo a un mandato familiar, Juan se mudó a la Capital para estudiar Comunicación en la UBA, y debió ejercer diversos trabajos para mantenerse. Entonces descubrió, comparándose con sus compañeros egresados del Colegio Nacional Buenos Aires (CNBA) o del Carlos Pellegrini ${ }^{12}$, como "nada de lo que él había estudiado en el secundario [le] servía" (DUKUEN, $2018 \mathrm{~b})^{13}$.

11. Las expectativas de prestigio asociadas a la figura de Bourdieu permiten comprender que la pertenencia a este universo pueda, en alguna medida, ser objeto de luttes de classement (BOURDIEU, 1979, p. 559). 12. Colegios secundarios de la UBA, a los que se ingresa por concurso.

13. "Bourdieu me permitió reelaborar la angustia que me generaba la situación", afirma Dukuen (2018b), quien en la idea de violencia simbólica encontró una clave para comprender su propia vida. 
Fue en las cátedras de Carlos Savransky y de Pablo Alabarces que accedió a las grandes obras de Bourdieu. Terminado el grado, decidió realizar su tesis sobre Bourdieu y Merleau-Ponty ${ }^{14}$. Hizo su doctorado con una beca del CONICET, con la dirección de Graciela Ralón de Walton, una filósofa experta en Merleau Ponty, e ingresó a la CIC en 2016.

En su libro se centra en una tensión teórica no resuelta por la cual "el correlato de ajuste entre habitus y condiciones objetivas que fundamenta el correlato entre poder y violencia simbólica entra en contradicción con la ambigüedad e indeterminación de las prácticas y de la dialéctica de la institución del habitus" (DUKUEN, 2018a, p. 25). En la actualidad Dukuen está dedicado de lleno a la investigación empírica estudiando la incorporación de esquemas morales y disposiciones políticas en estudiantes secundarios de clase alta en una escuela de Buenos Aires (DUKUEN, 2018c).

Emiliano Gambarotta se autodefine como "un hijo de las clases medias urbanas” (GAMBAROTTA, 2018c). En su casa siempre se supo en qué consistía la Universidad: uno de sus abuelos ya era ingeniero recibido en la Universidad Nacional de La Plata (UNLP), y sus padres son ambos médicos. Hizo sus estudios primarios en la escuela pública y luego en el Liceo Víctor Mercante, uno de los tres establecimientos secundarios de la UNLP a los que se ingresa por riguroso sorteo público.

También Gambarotta llegó a Bourdieu de la mano de sus profesores en la Licenciatura en Sociología ${ }^{15}$ de la mano de Antonio Camou y de Carlos Prego "los profesores más brillantes que tuve" (GAMBAROTTA, 2018c). Ninguno de los dos podría ser considerado estrictamente como bourdieusiano. El primero hizo su Doctorado en Ciencia Política en la Flacso de México; el segundo, docente en la UNLP y en la UBA, muy versado en sociología de la ciencia, le hacía un espacio a Bourdieu en su curso de grado dedicado a las sociologías interpretativas.

En su beca del Conicet Gambarotta contó con la dirección de Alberto Pérez, otro de sus profesores de la UNLP, quien lo había introducido en la lectura de Adorno y Horkheimer. Cursando la Maestría en Sociología de la Cultura y Análisis Cultural ${ }^{16}$, conoció al sociólogo argentino Martin Plot quien sería su mentor para el doctorado ${ }^{17}$. Plot le aportaría a Gambarotta su conocimiento de Merleau-Ponty que le resultaría clave para cerrar la brecha entre los frankfurtianos y Bourdieu: “ahí -en Merleau Ponty- estaba la conexión entre cierta reflexividad bourdieusiana y cierta concepción de la dialéctica que yo venía trabajando, para mí fue como un momento gestáltico..." (GAMBAROTTA, 2018c).

14. En esta tarea reconoce su deuda con la obra de Ana Teresa Martínez (2006).

15. Sociología en La Plata es una de las carreras con mayor presencia de Bourdieu: en un relevamiento reciente, aparecían escritos suyos en las bibliografías de un 43\% de las asignaturas (BARANGER, 2013, p. 176).

16. Postgrado fundado en 1992 por Carlos Altamirano y Beatriz Sarlo en la Escuela de Altos Estudios Sociales de la Fundación Patricios, dirigida por José Nun, y luego absorbida como Instituto de Altos Estudios Sociales (Idaes) por la Unsam.

17. Antes de partir hacia los Estados Unidos, dónde realizó su tesis en la New School for Social Research en Nueva York, M. Plot había integrado la cátedra de C. Savransky en la FCS-UBA. 
Esta fue la base de su tesis, y de su primer libro (GAMBAROTTA, 2014). Más recientemente, en Bourdieu y lo politico (GAMBAROTTA, 2018a), Gambarotta explora uno de los puntos ciegos de la teoría de Bourdieu, haciendo lugar a la postura de Rancière, pero también de Laclau y Mouffe. Para él, "en una lógica bourdieusiana pero también frankfurtiana -, este tipo de discusiones, teóricas, son siempre análisis sobre la sociedad contemporánea (Lukács no se piensa a sí mismo como un teórico)" (GAMBAROTTA, 2018c). Gambarotta exhibe un gran talento para el análisis teórico, sin que esto excluya su capacidad para desarrollar estudios empíricos sobre ideologías y opiniones políticas (GAMBAROTTA, 2018b).

\subsection{Después de Bourdieu, en sus dominios}

Otros han llegado a Bourdieu yendo a abrevar directamente en sus fuentes. Eleonora Elguezábal, contemporánea de Dukuen y Gambarotta, hizo todos sus estudios universitarios en Francia, y es actualmente investigadora en el Institut National de la Recherche Agronomique (INRA). Sus dos artículos publicados en Actes (ELGUEZÁBAL, 2014b; 2016) habilitan adscribirla a la constelación bourdieusiana, a la vez que el tema de su tesis y su trabajo de campo, unidos a la reciente presentación de la traducción al español de su libro (ELGUEZÁBAL, 2018b), la muestran con un pie en Buenos Aires.

Nacida en Buenos Aires de padres arquitectos, cursó sus estudios primarios en la Escuela "Primera Junta" de Caballito, y los secundarios en el turno mañana del
CNBA. Comenzó estudiando Historia y Derecho en la UBA. En la época del "1 a 1"18, hizo el cálculo de que seis meses en Francia le costarían lo mismo que un año en la Alliance Française de Buenos Aires, y viajó para perfeccionar su francés. Con la crisis final de la convertibilidad decidió quedarse en Francia, y luego de un año en Nanterre ingresó por la selección internacional a la École Normale Supérieure. En la ENS, donde estuvo muy ligada a antropólogos (Benoît de l'Étoile fue inicialmente su tutor), entró directamente a trabajar en investigación. En el mismo edificio funcionaba el Laboratoire de Sciences Sociales que era ENS-EHESS. En general eran "investigadores muy ligados a Bourdieu pero no al CSE; más bien ligados a Chamboredon, bourdieusianos pero no duros: [...] Bourdieu está muy bien pero vamos a leer a los otros" (ELGUEZÁBAL, 2018a).

En sus estudios de maestría Elguezábal fue dirigida sucesivamente por Olivier Schwartz, sociólogo de la clase obrera, y por la antropóloga Florence Weber. Luego en su doctorado lo fue por Christian Topalov, y su tesis La production des frontières urbaines: les mondes sociaux des "copropriétés fermées" à Buenos Aires (ELGUEZÁBAL, 2014a) fue premiada como la mejor de la EHESS en 2011.

Durante los cinco años de su doctorado viajó todos los segundos semestres a Buenos Aires para hacer su trabajo de campo, y ya en 2009-2011 como participante, por vía de F. Weber, de un proyecto entre el Centre Maurice Halbwachs y el Idaes-Unsam. En 2016-2017 en el marco de otro proyecto conjunto con el Idaes, dictó un curso para el Doctorado de Sociología sobre "Juegos de escala” de Revel.

18. "1 peso argentino = un dólar", sobrevaluación del tipo de cambio impuesta por la "Ley de convertibilidad” del Gobierno de Menem para eliminar la inflación. 
Al publicar su libro en español, "le pregunté a Ariel [Wilkis] si me podían dar una sala” (ELGUEZÁBAL, 2018a), la presentación se hizo en abril de 2018 en la Sede Volta de la Unsam.

En el INRA, su locus es el Centre d'Économie et de Sociologie Appliquées aux Espaces Ruraux (CESAER) en Dijon, un laboratorio que trabaja sobre las transformaciones del mundo rural. Desde allí enuncia sus diferencias con Bourdieu:

Una de las cosas interesantes trabajando sobre los espacios rurales es la dimensión espacial de la estructura social, [sobre la cual] en Bourdieu es casi nula la teorización: está Effets de lieux, y nada más. [...] En Bourdieu es una teoría macro muy basada en estadística, en el ACM; uno observa algo y lo remite a qué lugar ocupa en ese espacio. [...] la posición está siempre marcada por lo macro, no es micro de base. Hasta en los etnógrafos más etnógrafos bourdieusianos hay una contradicción importante. Es lo que nos pasa cuando estudiamos la cuestión de la dimensión espacial, porque la estructura social en el espacio rural no es la misma que en la urbana (ELGUEZÁBAL, 2018a).

Gabriel Vommaro es el otro argentino que ha publicado en Actes en los últimos años (COMBES e VOMMARO, 2017) ${ }^{19}$. Vommaro se autoidentifica como "sociólogo político”, y es otro caso de apropiación individual a partir de estudios de postgrado realizados en Francia. Nació en 1976 en Buenos Aires, hizo sus estudios primarios en una escuela pública de Caballito, y los secundarios en el Carlos Pellegrini de la UBA. Sus padres son médicos y en su casa reinaba un clima familiar con un alto interés en la política.

Pensó en estudiar Economía, pero finalmente su sensibilidad más literaria que científico-matemática lo llevó a Sociología en la UBA. Fue al cursar Sociología General con Ricardo Sidicaro y Lucas Rubinich cuando leyó Los estudiantes y la cultura de Bourdieu y Passeron, y se fascinó; pero también reconoce la fuerte influencia de Carlos Prego en "Teoría Social Contemporánea: la corriente interpretativa”, cátedra a la que luego se integró como ayudante; allí se adentró en El sentido práctico (BOURDIEU, 2007), La distinción (BOURDIEU, 1988) y Meditaciones pascalianas (BOURDIEU, 2006), entre otros textos de Bourdieu.

Comenzó a trabajar en investigación con Isidoro Cheresky, quien le acercó un ejemplar de Faire l'opinion (VOMMARO, 2018) y lo impulsó a realizar estudios de postgrado en Francia, y así llegó en 2003 al CSE para trabajar con Patrick Champagne quien dirigiría su DEA y su tesis doctoral. El ambiente en el CSE era aún mortuorio: "era un velorio, la casa del padre muerto, la gente se arrastraba por los pasillos" (Vommaro, 2018). Al lado, florecía la sociología de la crítica de Luc Boltanski: "seguí su seminario dos años (Latour estaba siempre invitado ahí), también [estuve] dos años con Lemieux" (VOMMARO, 2018). Además, cursó con Champagne, Serge Paugam y Robert Castel.

Por indicación de M. de Saint-Martin se relacionó con Michel Offerlé llegando a entablar relaciones de amistad, al igual que con Gérard Mauger. Offerlé lo invitó a su grupo de estudios - el GRIP, Groupe de Recherches Interdisciplinaires sur la Javier Auyero (2005), Alicia Gutiérrez (2005) y Gustavo Sorá (1999; 2002) [ver infra]. 
Politique -, y le presentó a la politóloga Hélène Combes, su coautora en Actes y en un libro publicado por La découverte y luego en español por Siglo XXI (VOMMARO e COMBES, 2016). Vommaro explicita qué lo separa de Bourdieu:

Yo no me siento un bourdieusiano ortodoxo [...]si la política es un ámbito en que la reflexividad, el cálculo, la estrategia [...] pero también la dimensión cognitivo-moral es fundamental, es el punto débil de la teoría de Bourdieu: no tiene una clara definición de qué lugar tendría eso en el modo en que los actores elaboran su práctica [...] No permite pensar la política; ésta es disimulación, pero también explicitación, controversia, disputa, y eso supone construir argumentos. [...] Cuando hacés etnografía política ves que los actores ponen de manifiesto las cosas más que las ocultan y que esto hace a la interacción política, que es muy importante [...] Uso a Bourdieu como gran inspiración y como gran esquema, pero con mis diferencias en cuanto a su operatividad para pensar la política (WILKIS, 2018).

Por su parte, Ariel Wilkis se crió en un hogar de universitarios (padre contador y madre historiadora del arte) en el barrio porteño de Palermo. Es amigo de Vommaro: cursaron juntos el secundario en el Pellegrini, y toda la licenciatura en Sociología.

A Bourdieu llegó primero con R. Sidicaro y luego con C. Prego. Se inició en investigación con Arturo Fernández, politólogo, trabajando sobre temas sindicales, y luego, con una beca del Conicet, sobre temas de pobreza. Hizo en la UBA su Maestría en Investigación, y eligió continuar sus estudios en Francia porque había un camino: "Sidicaro venía de allí, y había también una fuerte presencia dinámica del CFA" (WILKIS, 2018). Eran años de máximo esplendor de Bourdieu y de Robert Castel: "Para quien más menos estábamos vinculados a la cuestión social, era Francia” (WILKIS, 2018). Influyó en su decisión Lygia Sigaud, a quien conoció en 2004 cuando vino a dar un curso en la FFyL: "ella fue muy importante, pensaba teoría social pero con un enfoque etnográfico muy potente, combinación no fácil de encontrar en sociología” $\left(\right.$ WILKIS, 2018) ${ }^{20}$. Lygia le insistió en que fuera a la EHESS y le dio su red: Florence Weber, Stéphane Beaud, Afrânio Garcia...

Vommaro fue quien lo conectó con Mauger, quien aceptó recibirlo como doctorando.

A su llegada al CSE, cuando le contó a un tesista de Mauger que pensaba investigar sobre la dimensión moral de las prácticas económicas, la respuesta fue "eso aquí no se estudia”, y que para ello haría mejor en dirigirse a Boltanski. Enfocado en esa cuestión de moral y economía, Wilkis (2014) trabajaría sobre el concepto de capital moral, sin terminar nunca de convencerlo a Mauger: "me daba cuenta de que mi sociología tenía atisbos del razonamiento sociológico bourdieusiano, pero no compraba el paquete entero" (WILKIS, 2018).

Wilkis entiende el capital simbólico menos como un concepto y más como un programa de investigación consistente en explorar sus distintas especies. Así como en el concepto de capital agonístico de Mauger se trata del reconocimiento de virtudes en el uso de la fuerza física; el capital moral sería un concepto derivado de ese mismo 
programa. Supondría un retorno a una lectura más fina del Bourdieu de Cabilia, una lectura más maussiana de Bourdieu.

En la actualidad, Wilkis no se identifica como bourdieusiano, prefiere incluirse en la categoría de quienes se han vinculado con algo perteneciente a "la galaxia bourdieusiana”. Esto no le ha impedido dar un curso sobre Bourdieu en Santa Fe desde 2008 en adelante $^{21}$, al que luego le sumó Elias, ya que considera que El proceso de civilización (ELIAS, 1989) brinda una visión más abarcadora que la de Bourdieu.

Reconoce que las ideas centrales de su trabajo fueron inspiradas por Viviana Zelizer a partir del 2008 (WILKIS, 2013, p. 18). Últimamente Wilkis viaja a la New School y a Princeton, y no a París. "La academia francesa ha perdido en la geopolítica global frente a la norteamericana. [...] La sociología francesa la encuentro aún inspiradora, pero aspiradora también: difícil no comprar todo el paquete: Bourdieu, los pragmatistas..." (WILKIS, 2018). Zelizer funciona como una fuente que lo internacionaliza por fuera de Francia: "publico en Stanford como un discípulo de ella que intenta vincularla con Bourdieu" (WILKIS, 2018) ${ }^{22}$.

Wilkis y Vommaro codirigen la colección Sociedades contemporáneas en la Editorial Antropofagia del antropólogo Santiago Alvarez. En la misma, además de Mauger (2007), han publicado libros de Karsenti (2008), Dufy y Weber (2009), Offerlé (2011) y Beaud y Pialoux (2015) ${ }^{23}$.
Wilkis es ahora el Decano de la Unsam, una institución que, habiendo absorbido el Idaes, ha crecido muy rápidamente en el área de las ciencias sociales, reclutando investigadores del Conicet procedentes de otras universidades ${ }^{24}$.

En el Centro de Estudios Sociales de la Economía (Cese) del Idaes participa Mariana Heredia ${ }^{25}$, quien hizo su tesis en la EHESS en 2001-2006 bajo la dirección de M. de Saint-Martin. En un artículo reciente, Heredia discute sobre las nociones de campo y de red aplicadas al estudio de la profesión de economista; y constata: "la falta de un diálogo empíricamente fundado entre los herederos de Bourdieu y los acólitos de Callon y Latour ha tendido a limitar las controversias a una discusión teórica muy abstracta” (HEREDIA, 2016, p. 65). Según ella, en la tradición de Bourdieu la "distinción entre heterodoxia y ortodoxia adquiere cierta rigidez a lo largo del tiempo y se agota en las preferencias ideológicas" (HEREDIA, 2016, p. 66). Tal vez una autocrítica su propia descripción anterior del campo de los economistas en la Argentina (HEREDIA, 2015) en base a aquel único eje.

En la Unsam se edita Papeles de trabajo, en la cual el pensamiento vinculado a Bourdieu tiene una importancia significativa; con una década de trayectoria, la revista se ha impuesto como una pieza importante en el desarrollo del Idaes.

21. Fue convocado por R. Sidicaro en reemplazo de A. T. Martínez.

22. Ver Wilkis (2018b).

23. Juntos han escrito una reseña del libro de Beaud y Pialoux, a la que presentan como un texto programático acerca de cómo usar a Bourdieu en modo empírico (VOMMARO e WILKIS, 2015).

24. Agrupa actualmente unos 200 becarios e investigadores (WILKIS e GARRIGA, 2018). Últimas incorporaciones en el mercado académico de pases: Emiliano Gambarotta y Gabriel Vommaro.

25. Heredia participa también de la revista Apuntes de Investigación [ver infra]. 


\subsection{Décadas atrás: la matriz de Punto de Vista}

Alejandro Blanco se autodefine como un miraculé. Nacido en una familia de trabajadores rurales de Gualeguaychú (Entre Ríos), en sus dos linajes los únicos diplomados son él y sus hermanos. Su madre completó la primaria; su padre por la tuberculosis debió interrumpir sus estudios en tercer año del secundario. En aspiraciones paternas no realizadas encuentra la explicación de ese milagro: "alguien de la familia tiene que tener algo que cambie la inercia de la trayectoria" (BLANCO, 2018).

Blanco consiguió ingresar al Monserrat de Córdoba, colegio jesuita de clase alta, en el cual se sentía la oveja negra. Aprobó hasta el quinto año (de un total de siete), pero le bastó para aprender griego, latín, francés e inglés, antes de regresar a Gualeguaychú donde finalizó el secundario.

En Sociología de la UBA ingresó en 1985, $\mathrm{y}$ tuvo que trabajar vendiendo corbatas durante toda su carrera. No fue alumno de Sidicaro (quien "coacheó a todo el grupo de la Unsam”) ni de Emilio Tenti Fanfani (en cuya cátedra colaboró, enseñando a Bourdieu y Elias) ${ }^{26}$; sí cursó con C. Prego quien, además de Bourdieu, le dejó a Mannheim.

Fue reclutado por C. Altamirano con una beca entre 1998 y 2001, con la cual dio inicio a la investigación que lo conduciría al doctorado. Desde entonces está asentado en la Unqui en el Programa de Historia Intelectual.
Durante el cursado la Maestría en Sociología de la Cultura en el Idaes de José Nun, recibió otra buena dosis de Bourdieu: "allí estaba el grupo de los primeros bourdieusianos: Sarlo, Altamirano, y tutti quanti" (BLANCO, 2018).

Fino lector, en sus inicios su vocación era más literaria que sociológica. Su primera publicación en Punto de Vista (BLANCO, 1995) fue una entrevista a José Saer, que le fue "capturada" por Sarlo. Se convirtió en colaborador habitual de esta revista de crítica cultural, donde publicó su primer texto sobre Bourdieu: una reseña de La miseria del mundo.

Su tema de tesis doctoral - Germani le fue propuesto por Altamirano y Oscar Terán. Defendió su tesis en Historia en la FFyL-UBA en 2005, y a renglón seguido la publicó como libro (BLANCO, 2006), convirtiéndose de inmediato en una obra de referencia sobre la fundación de la sociología científica argentina por Germani. Ingresó a la CIC del Conicet como Adjunto en 2008.

En 2005 conoció al paulista Sergio Miceli y a miembros de su grupo, cuando éste fue invitado por el Centro de Historia Intelectual ${ }^{27}$. Luego, en el 2008, Luiz Jackson, discípulo de Miceli, vino a Quilmes a hacer un postdoc con Blanco y desde entonces éste multiplicó sus contactos con Brasil, orientando los trabajos de varios paulistas y cariocas.

En el libro escrito en colaboración con Jackson, los autores analizan la institucionalización de las ciencias sociales entre 1930

26. Tenti fue Titular de Sociología de la Educación formando, entre otras discipulas, a Carina Kaplan (2007), hoy investigadora independiente de la CIC, que desarrolló la temática del "racismo de la inteligencia” en la senda de Bourdieu.

27. En esa misma ocasión entró en contacto con G. Sorá: "Con Gustavo tuvimos sociedades de proyectos, después con [Fernanda] Beigel. Somos como una troupe”. 
y 1970 en Argentina y Brasil, centrándose en las trayectorias de Florestan Fernandes y Gino Germani por la sociología, y de Adolfo Prieto y Antonio Candido por la crítica literaria (BLANCO e JACKSON, 2015).

En la trayectoria y en las obras de Bourdieu (pero también en las de Germani), encuentra Blanco temas de fuerte resonancia con sus propias circunstancias vitales: la migración, la distancia social y cultural, la allodoxia. "A mí me gusta Bourdieu por una cuestión de mi propia biografía, uno se identifica: lo emocional y lo biográfico no están desligados de la elección de autores. Cuando leí Esbozo de un autoanálisis fue la locura, otra cosa [sería] si él hubiera sido un mandarin" (BLANCO, 2018).

\subsection{De Apuntes de Investigación a la aca- demia norteamericana}

Lucas Rubinich se formó también en la matriz de Punto de vista, aunque algunos años antes. La carrera de Sociología que cursó en la UBA nada tuvo que ver con la de Blanco. Eran tiempos de dictadura, y la Facultad se había visto reducida a un lugar para aprobar materias y obtener un título; por lo cual, según una modalidad típicamente argentina, la formación se obtenía en grupos de estudio, por fuera de la universidad.

Criado en una casa sin auto ni televisión - aunque ubicada en pleno centro de la provinciana Arrecifes (Buenos Aires) -, Rubinich terminó el secundario en el único colegio de la ciudad, y comenzó sus estudios poco antes del golpe de 1976. Cuando pudo graduarse en Sociología en 1982, ya había comenzado a adentrarse en Bourdieu por la vía de Beatriz Sarlo, en ese entonces investigadora en el CISEA, quien sería su directora de beca de Conicet en el CEDES ${ }^{28}$, donde cursó una suerte de especialización: "Beatriz era muy prestigiosa [...] con la potencialidad de la apertura democrática Punto de vista pesaba más que un doctorado en USA" (RUBINICH, 2008).

Luego, al retornar de Francia R. Sidicaro, comenzó a colaborar con éste en la cátedra de Sociología General, y de ahí en más se afincó en la FCS, cultivando un perfil netamente docente. Ocupó en cuatro oportunidades la dirección de la carrera de Sociología, y sus publicaciones han tenido mayormente que ver con el rol y la inserción profesional de los sociólogos (e.g., RUBINICH e BELTRÁN, 2010).

En sus inicios como docente, Rubinich se inventó un grupo de estudio con alumnos del grado. Ente éstos se contaban Javier Auyero y Claudio Benzecry, quienes desarrollarían brillantes carreras en el país del Norte, aunque sin dejar de jugar en el tablero argentino.

Javier Auyero es uno de los siete argentinos que publicó en Actes (AUYER0, 2005), en la cual acaba también de ser objeto de una entrevista (AUYERO, 2019). Graduado en Sociología en 1991, se doctoró en la New School for Social Research en 1997 con la dirección de Charles Tilly. Desde entonces se ha convertido en un referente insoslayable en la temática del clientelismo político, y no ha dejado nunca de reconocer su deuda intelectual con Bourdieu y Wacquant (Hurtado Arroba, 2005) en cuanto a la teoría y a la práctica de la etnografía.

28. El Centro de Estudios de Estado y Sociedad (CEDES) y el Centro de Investigaciones sobre la Sociedad, el Estado y la Administración (CISEA) fueron dos de los centros de investigación en los que encontraron refugio las ciencias sociales durante la última dictadura (MURMIS, 2005, p. 259). 
Claudio Benzecry, después de graduarse en Ciencia Política en 1997, prosiguió sus estudios en la Maestría del IDAES. Su disertación doctoral del 2007 en la New York University versó sobre los fanáticos de la ópera en el Colón; el libro resultante fue publicado en inglés (BENZECRY, 2011) y resultó premiado por dos veces por la $\mathrm{ASA}^{29}$. Recientemente en un dossier en Cuestiones de sociología centrado en los aportes pragmatistas con relación a Bourdieu (NARDACCHIONE e PIOVANI, 2017) ha ahondado en la evolución de la noción de habitus en Bourdieu y en su recepción en los Estados Unidos (BENZECRY, 2017).

Tanto Auyero como Benzecry ${ }^{30}$ continúan integrando el Comité editorial de Apuntes de Investigación, revista creada en 1997 y dirigida por Rubinich, cuyo primer número presentaba artículos de Charles Tilly (el advisor de Auyero en su disertación doctoral) y de Loïc. J. Wacquant. Fue idea de Wacquant plantear una suerte de hermanazgo entre Apuntes y Actes de la recherche (perceptible en su título mismo). En el cuarto número - "Intelectuales" - se publicaría en español por vez primera el artículo de Bourdieu y Wacquant "Sobre las astucias de la razón imperialista” (1999).

También el cordobés Paul Hathazy, graduado en abogacía, publicó un artículo (HATHAZY, 2006) en Apuntes durante su estancia en Berkeley, donde obtuvo su PhD en 2013. Elaboró su tesis Democratizing Leviathan: Bureaucrats, Experts and Politics in the Transformation of the Penal State in Argentina and Chile (HATHAZY, 2013), con la dirección de Loïc Wacquant, y en contacto con Javier Auyero. Reincorporado a Córdoba como Investigador Adjunto de la CIC ya en 2015, Hathazy, junto a la antropóloga Sabina Frederic, viene de coordinar un dossier sobre "Trabajo policial y política" en la revista Trabajo y Sociedad de Santiago del Estero (HATHAZY e FREDERIC, 2018).

Transcurridas sus dos primeras décadas de existencia Apuntes de investigación continúa siendo una revista de las más prestigiosas entre las publicaciones locales sobre sociología de la cultura, abierta a las colaboraciones de antropólogos e historiadores.

\subsection{Alicia Gutiérrez: Espacio social y estra- tegias de reproducción}

Alicia B. Gutiérrez cursó la primaria en la escuela pública, la secundaria en la Escuela Manuel Belgrano de la Universidad Nacional de Córdoba (UNC), y se graduó en Historia en la UNC. Para su Doctorado realizaría luego una tesis sobre estrategias de reproducción entre pobres urbanos (GUTIÉRREZ, 2004), en cotutela con la dirección del antropólogo Carlos Herrán por la FFyLUBA y del sociólogo Jean-Claude Combessie $^{31}$ por la EHESS. En su estancia parisina lo llegó a conocer a Bourdieu ${ }^{32}$.

En 1994 saltó a la fama con un pequeño libro sobre el sistema teórico de Bourdieu, que tuvo una enorme difusión y se con-

29. En 2016, Benzecry fue galardonado con un premio Konex en Sociología.

30. Ambos se asociaron recientemente para producir un artículo sobre el habitus clientelar (Auyero y Benzecry, 2017).

31. Combessie dirigió al CSE, junto a Monique de Saint-Martin.

32. Todavía hoy Gutiérrez es reconocida como Corresponsal extranjera en el Centre Européen de Sociologie et de Science Politique (CESSP), nacido en enero de 2010 de la fusión del CSE y del Centre de Recherches Politiques de la Sorbonne (CRPS). 
virtió en un texto de referencia, habiendo sido editado en cuatro ocasiones en España y en Argentina (GUTIÉRREZ, 2012). Además de realizar una reconocida labor de traducción de libros (e.g., BOURDIEU, 2013a), y artículos en numerosas compilaciones (e.g., BOURDIEU, 2011), Gutiérrez sigue embarcada en una muy intensa actividad de dictado de cursos, en una plétora de universidades argentinas, de América Latina (Chile, Colombia. y México) y Europa (España, Francia, Italia).

En su programa de investigación, ha venido analizando sistemáticamente las principales estrategias de reproducción social (laborales, educativas, habitacionales y de consumo cultural) de las distintas clases y fracciones de clase de la sociedad cordobesa, y las representaciones implicadas en estas prácticas para dar cuenta de la dinámica de las desigualdades y de las relaciones de poder que estructuran el espacio social.

Para ello ha convocado un gran número de colaboradores, diez de los cuales se doctoraron con su dirección. Pieza clave en el equipo es Héctor Mansilla, un estadístico especializado en los métodos multidimensionales de análisis y doctorado en la FCSUBA en 2016. Sobre datos secundarios de la Encuesta Permanente de Hogares (EPH), Mansilla construyó en base a un Análisis de Correspondencias Múltiples (ACM) el espacio de las clases sociales en Córdoba (GUTIÉRREZ y MANSILLA, 2004), destinado a funcionar como esquema de fondo para los estudios de índole más cualitativa realizados por los otros miembros del equipo.

La mayoría de sus colaboradores pudieron doctorarse gracias a becas del Conicet. Así, Julieta Capdevielle lo hizo en la UNC en 2013 con una tesis sobre el capital social y las estrategias de reproducción en familias de iglesias evangélicas en contexto de po- breza. Ingresada a la CIC, se ha volcado al estudio de las estrategias habitacionales de resistencia frente al avance del mercado inmobiliario Córdoba (CAPDEVIELLE, 2017).

Por su parte, Gonzalo Assusa egresó como sociólogo de la Universidad N. de Villa María y obtuvo en 2016 el Doctorado en Antropología en la UNC estudiando la "cultura del trabajo" entre jóvenes de clases populares (ASSUSA, 2017; 2018). Al analizar los repertorios morales puestos en juego por jóvenes de sectores populares con relación a las políticas de empleo, no vacila en acudir a aportes de Boltanski, Grignon y Passeron o F. Weber.

Cecilia Jiménez Zunino nació en San Juan en 1976 de padres estudiantes de derecho, concurrió a la escuela pública del barrio popular al cual sus padres se habían mudado en razón de su militancia, y cursó luego el secundario en el colegio universitario. En la Universidad Nacional de San Juan (USJN) comenzó estudiando Trabajo Social pero luego del primer año se pasó a Sociología. En el 2001 partió hacia Madrid y se inscribió en la U. Complutense donde obtuvo el DEA en 2003 y el doctorado en 2013 con una tesis sobre Desclasamiento y reconversiones en las trayectorias de los migrantes argentinos de clases medias (JIMÉNEZ ZUNINO, 2013). Ingresó a la CIC como Asistente en 2013 con la dirección de A. Gutiérrez, siendo luego promocionada a Adjunta. Últimamente ha estudiado trayectorias intergeneracionales en sectores medios cordobeses en relación con el desarrollo de la industria automotriz (JIMÉNEZ ZUNINO, 2016).

\subsection{Fernanda Beigel: Dependencia acadé- mica en América Latina}

Hija de un comerciante que no terminó la primaria, y de una trabajadora social, que 
llegó a hacer una maestría en Brasil, Fernanda Beigel nació en Buenos Aires, donde cursó cuatro años en una escuela pública antes de viajar a USA dónde completó la primaria. Radicada su familia en Mendoza realizó el secundario en la Escuela de Magisterio de la UNCU.

En 1993 se graduó como socióloga con medalla de oro. Hizo una tesis dirigida por Arturo Roig sobre el recorrido estético-político de José Carlos Mariátegui con la que obtuvo el doctorado en la UNCU en 2001.

En el CESSP su principal referente es Gisèle Sapiro. En 2003, luego de ganar el premio Houssay del Conicet, Beigel quería conocer el CSE y para ello se comunicó con Sapiro, quien le sugirió contactarse con Gustavo Sorá ${ }^{3}$. Luego, gracias a un premio de Clacso, pudo Beigel realizar una primera estancia postdoctoral en la EHESS con Sapiro en 2004. En aquella estadía conoció también a Yves Dezalay, Afrânio Garcia, y Sergio Miceli, con quiénes entabló relaciones académicas cada vez más fluidas hasta invitarlos a un coloquio sobre Bourdieu que organizó en Mendoza en 2006.

Desde 2004 Beigel dirige el Programa de Investigaciones sobre Dependencia Académica en América Latina (PIDAAL), cuya orientación bourdieusiana se fue acentuando más y más, desembocando en un conjunto de investigaciones sociológicas sobre las ciencias sociales único en Argentina.

Beigel ha venido trabajando con un gran número de colaboradores, de los cuales diez se han doctorado con su dirección ${ }^{34}$. En la actualidad, su equipo lo integran tres beca- rios postdoctorales, y seis investigadores de la CIC, además de ocho docentes-investigadores de la UNCU. Convencida de las potencialidades de los métodos multivariados, Beigel organizó en 2014 para su equipo un curso intensivo de ACM, recurriendo a Brigitte Leroux, Frédéric Lebaron y Johannes Hjellbrekke, quienes viajaron especialmente a Mendoza para realizarlo.

Del conjunto de colegas que entrevisté, Beigel aparece como la más internacionalizada, con una vastísima producción y una más que intensa participación en foros internacionales. Muestra de ello son sus recientes artículos en Dados (2017) y en $M i$ nerva (BEIGEL, GALLARDO e BEKERMAN, 2018), donde discute sobre los resultados más recientes del PIDAAL.

Entre las numerosas discípulas de Beigel se encuntra Fabiana Bekerman, nacida en Mendoza, graduada en sociología en la UNSJ en 2003. Desde 2006 a 2014 tuvo becas del Conicet dirigida por Beigel, defendiendo en 2012 en la UNCU su tesis doctoral sobre la estructura del campo científico argentino bajo la dictadura ${ }^{35}$. Ingresó a la CIC en 2014 siendo promovida a Adjunta en 2018.

Maximiliano Salatino es mendocino e hizo toda su carrera como becario del Conicet dirigido por Beigel. Egresó de Ciencia Política de la UNCU, y defendió exitosamente en 2018 su tesis doctoral sobre la estructura del campo de las publicaciones científicas en América Latina. En su último artículo compara los circuitos de publicación en Argentina y en Brasil (SALATINO, 2018).

33. De alli surgió la invitación para que Sorá diera un curso en Mendoza en abril 2004.

34. El libro editado por Beigel en Ashgate (2012), es una buena muestra del trabajo realizado por los miembros de su equipo. 


\subsection{Gustavo Sorá: Todo por los libros}

Gustavo Sorá se crió en La Plata en una casa de clase media repleta de libros y de vinilos. Hizo sus estudios en la escuela pública, y aprobó el ingreso por riguroso concurso al Colegio Nacional de la UNLP. De mis entrevistados, es el único antropólogo "puro": hizo su grado en el Museo de la UNLP, su Doctorado en el Museo Nacional de Rio de Janeiro, y su lugar de trabajo actual es en el Museo de Antropología en Córdoba donde se afincó a su retorno de Brasil.

El objeto privilegiado de Sorá es el libro. Amante de la literatura, y apasionado por la música, su aspiración sería "hacer ciencias sociales como Jaco Pastorius o Pedro Aznar tocaba/toca el bajo, o con el vuelo de Spinetta o Dino Saluzzi” (SORÁ, 2018).

Para Sorá, su formación en el Programa de Post-Graduação em Antropología Social (el PPGAS-UFRJ) - uno de los hauts lieux de la antropología mundial ${ }^{35}$-, fue un "shock intelectual” (SORÁ, 2018). Reconoce dos características fundamentales de esa institución. Por un lado, la liberación del pensamiento, superando las fronteras morales entre paradigmas y disciplinas: “ $\mathrm{iMarx}$ podía ir junto a Weber!, ¡Bourdieu no necesariamente era incompatible con Geertz! Tanto Morgan, como Boas, Malinowski o Evans-Pritchard tenían cosas magistrales para aprender y utilizar en la reflexión” (SORÁ, 2018). Por el otro, "el contacto directo con los productores de ideas de países centrales [...], gente que uno pensaba que solo existía impresa o encerrada en libros” (SORÁ, 2018).
Trabajando con Afrânio García, su mentor, participaba de "las reuniones sociales intensas que se hacian con todos los investigadores franceses que iban a Río" (SORÁ, 2018). Así se dio su aproximación progresiva a investigadores del CSE, desde M. de Saint-Martin (quien lo recibiría en la EHESS en 1997), hasta miembros de su propia generación, como Gisèle Sapiro, quien en 1994 había terminado su tesis con Bourdieu sobre el campo literario francés bajo la ocupación (SAPIR0, 1999).

Sorá es de los pocos argentinos que conoció a Bourdieu, quien le encomendó realizar una etnografía de la Feria de Frankfurt (SORÁ, 1998) ${ }^{36}$. Desde entonces sus temas de investigación han tenido que ver con el libro, la edición y la traducción, hasta llegar a su atrapante historia (SORÁ, 2017) del Fondo de cultura económica y de Siglo XXI, centrada en la figura del editor Arnaldo Orfila.

Sorá asume sin complejos su inspiración en Bourdieu: “está en todos mis trabajos por hipótesis, áreas temáticas y orientaciones prácticas (o metodológicas)" (SORÁ, 2018). Sin que esto implique dogmatismo alguno: para él, la idea misma de una ortodoxia bourdieusiana sería un oxímoron, la peor traición que se podría infligir a la memoria del maestro.

Asume como una misión "divulgar a muchos de los investigadores de la red del CSE desconocidos o no traducidos al español” (SORÁ, 2018). Es así en que en Eduvim codirige la colección Entreculturas, en la que ya han editado libros con compilaciones de

35. Son numerosos los antropólogos argentinos que se han doctorado allí.

36. En 1994 Sorá había finalizado su tesis de maestría en el Museo de Rio, con el musical título de "Livros de uma exposição. Etnografia das bienais internacionais de livros do Rio de Janeiro e São Paulo”. 
artículos de Joseph Jurt (2014), Yves Dezalay y Bryant Garth (2017) ${ }^{37}$, Gisèle Sapiro (2018b) y Sophie Noel (2018).

Alejandro Dujovne comparte la pasión por el libro de su maestro Sorá. Es hijo de un médico y de una doctora en Ciencias Químicas, ambos descendientes de "gauchos judíos" que terminaron recalando en Córdoba.

Hizo sus estudios secundarios en un colegio público de buena reputación y, como en Córdoba no había Antropología ni Sociología, terminó estudiando Ciencia Política en la Universidad Católica. A Bourdieu lo descubrió en la Maestría de Antropología con Gustavo Sorá y Alicia Gutiérrez.

En 2005 con la beca del CONICET comenzó en Buenos Aires el doctorado en el IDES-UNGS, donde Sorá enseñaba Bourdieu. Su tesis fue defendida en 2010, y dio lugar a un libro (DUJOVNE, 2014), en el que "hubo por lo menos una pretensión de contar esa historia desde un esquema bourdieusiano, pero nada escolástico" (DUJOVNE, 2018). Con Sorá avanzó en la temática de la circulación de las ideas y forjó un buen vínculo con Joseph Jurt, traduciendo algunos de sus textos.

En 2011 al llegar al CESSP con una beca postdoc, para una estadía de seis meses, ya tenía ese interés por la lectura y el campo intelectual, y se vinculó con Gisèle Sapiro: "Me fascinaba su carrera, Francia, Israel, y lo judío aparecía como una afinidad" (DUJOVNE, 2018). Fue el inicio de una colaboración que se extiende hasta la actualidad ${ }^{38}$.
A partir de allí fui [a Francia] casi todos los años, salvo éste. Inmediatamente que volví entré en un pequeño proyecto de Gisèle con Gustavo sobre circulación internacional de ideas y sociología del libro y la edición. En 2011 el Institut Français quería trabajar sobre la traducción de ciencias sociales y humanas francesas en Argentina, Giséle nos invitó a participar e hicimos un trabajito [...] Después se amplió en un proyecto más amplio con la Comunidad Europea que duró cuatro años (DUJOVNE, 2018).

Dujovne llegó a dirigir el IDES, tiene buenos contactos con el grupo de Quilmes de Historia Intelectual-Prismas y dirige ahora la Maestría de Análisis de la Cultura del Idaes en la Unsam. Lo sigue moviendo a nivel libidinal la política, pero como intervención pública: "Intervengo en los medios, escribo en diarios sobre temas de política del libro, y trabajo en la medida de lo posible con el Estado”. Así, en el Programa Sur de traducciones de la Cancillería participa ad honorem en el comité de selección de títulos a traducir ${ }^{39}$, a la vez que trabaja con distintos actores en un pack de leyes en Cámara de Diputados en defensa de la actividad librera y la promoción del mundo editorial.

\subsection{Gisèle Sapiro y el proyecto Interco-ssh}

Gisèle Sapiro ha llegado a ser la VicePresidente de Relaciones Internacionales de la EHESS. En los últimos años ha veni-

37. La compilación de este texto cuenta con un ensayo preliminar Paul Hathazy.

38. Dujovne también tradujo un artículo de Sapiro publicado en Prismas (2011).

39. “Argentina financia 150 libros al año. Editoriales extranjeras aplican y piden apoyo a la traducción”. 
do comandando el proyecto International Cooperation in the Social Sciences and $\mathrm{Hu}-$ manities (Interco-ssh), generosamente dotado por la Comunidad Europea, en el cual logró reunir a investigadores de primera línea de varios países europeos.

El objetivo de Interco-ssh fue evaluar el estado de las ciencias sociales y humanidades en Europa y comprender los factores que facilitan u obstruyen los intercambios internacionales, recurriendo a las herramientas de las ciencias sociales y humanidades para estudiarlas en su contexto socio-histórico. Para ello se propuso comparar el proceso de institucionalización de siete disciplinas académicas - Economía, Sociología/Demografía, Ciencia Política, Antropología, Filosofía, Literatura, Psicología/Psicoanálisis - en búsqueda de identificar los factores sociológicos que han conformado el "inconsciente académico" de los científicos. El foco estuvo puesto en la transferencia de conocimiento entre países y disciplinas, en la movilidad geográfica de los científicos y en la circulación de las ideas ${ }^{40}$.

El proyecto tiene un capítulo latinoamericano, coordinado por Gustavo Sorá, para lo cual se convocó a varios investigadores de Brasil y de Argentina ${ }^{41}$. En este contexto se incorporaron Beigel y Dujovne, así como M. Heredia y A. Wilkis ${ }^{42}$, quienes en 2016 editaron un dossier en Papeles de trabajo sobre "Internacionalización de las ciencias sociales" (HEREDIA; WILKIS, 2016), con varias traducciones de artículos (incluyendo uno de J. Heilbron, 2016) y, entre otras, contribuciones de Dujovne (2016), y de María P. López (2016). Por Literatura, fue convocada Analía Gerbaudo, quien en Santa Fe edita la revista El taco en la brea, para la cual ha traducido artículos de Sapiro (2017; 2018a). También participaron Mariana Canavese (Investigadora de la CIC en el Centro de Documentación e Investigación de la Cultura de Izquierdas de la Unsam), una historiadora especializada en la recepción de Foucault en Argentina, y la psicóloga Alejandra Golcman (de la U.N. de Tucumán) por Psicología.

Entre los resultados del Proyecto, cabe destacar la colección de tres libros que está editando Palgrave-MacMillan. El volumen coordinado por Heilbron, Sorá y Boncourt (2018) ha sido el primero en salir, y es el más "latinoamericano", con capítulos de Blanco y Wilkis, Sorá y Blanco, Sorá y Dujovne, y Cánedo, además de contribuciones de otros autores europeos. En 2019 aparecerá - editado por Christian Fleck, Matthias Duller y Viktor Karády - un volumen sobre institucionalización, Shaping Human Science Disciplines (FLECK, DULLER e KARADY, 2019), con un capítulo de Beigel y Sorá.

\section{Conclusión: Bourdieu en el espacio de las ciencias sociales argentinas}

No tengo una teoría acerca de cómo se deviene bourdieusiano, ni creo que pueda haberla. Ese resultado, en gran medida contingente, obedece a una multiplicidad de factores que resultan en bifurcaciones de trayectorias individuales. Las sintéticas

40. Veáse la descripción del proyecto en su website < http://interco-ssh.eu/project-description/>.

41. Por el lado brasileño, colaboraron Leticia Bicalho Canêdo (Unicamp), Roberto Grün (Ufscar) y Afrânio García (desde el CESSP en la EHESS).

42. Sapiro lo reclutó a Wilkis, y fue por esta vía que éste conoció a Sorá y a Blanco. 
presentaciones prosopográficas de mis entrevistados han pretendidido ilustrar acerca de su trayectoria social y de su posición en el espacio de las ciencias sociales. Como se ha visto, la mayoría son de clase media, con padres universitarios $\mathrm{y}$, a veces, intelectuales. Otros provienen de hogares con menor capital escolar, aunque con gran fe en el valor de la educación, y han encontrado en las ideas de Bourdieu, y en su biografía, una imagen especular de su propia experiencia de la violencia simbólica.

Ciertamente, en los últimos años la producción en ciencias sociales ha conocido un espectacular aumento. Pero la gran cantidad de artículos publicados en la Argentina como en el extranjero, y lo nutrido de la oferta editorial no significan la existencia de una dinámica colectiva, así sea conflictiva, de construcción del conocimiento. Lo que se extraña en Argentina es la falta de disputas sustantivas de las cuales pudiera emerger un consenso, así fuera algo barroco, o múltiple en sus expresiones.

Las revistas se han multiplicado en las últimas décadas, sin que existan equivalentes en cuanto a la centralidad en un campo que pueden exhibir el American Journal of Sociology en Estados Unidos o la Revue Française de Sociologie en Francia ${ }^{43}$.

Es explicable la inabarcable proliferación de artículos, respondiendo al mandamiento publish or perish que el Conicet ha hecho suyo en gran medida. Pero en las ciencias sociales ésta no parece traducirse en un nivel de lecturas correlativo; ni siquiera la publicación en una revista presti- giosa garantiza la lectura de un artículo ${ }^{44}$. El incremento de la producción a niveles impensables en épocas anteriores es correlativo de una dispersión temática que favorece el aislamiento de los investigadores, en la ausencia de una agenda común. Es difícil hablar de campo, cuando quienes podrían conformarlo se ignoran unos a otros, ni siquiera por animosidad, sino con mayor frecuencia por simple desconocimiento.

A nivel global, el estado de la sociología se caracteriza por la coexistencia de paradigmas, potenciada a su vez por las diferencias que perduran entre las tradiciones nacionales. Pero en el contexto argentino, con una aún muy débil institucionalización de las ciencias sociales, los efectos disruptivos de la ausencia de un principio unificador, de un nomos como el que reclamaba Bourdieu (2001), se hacen sentir con mayor fuerza que en Francia o en Estados Unidos.

Si no hay propiamente un campo de la sociología en la Argentina, no es por falta de agentes ni de producción, sino por esa ausencia de una adecuada estructura institucional. Posiciones objetivas diferenciables no faltan, pero se carece de un eje ordenador común que exprese con alguna claridad lo que debería ser el "volumen del capital sociológico", y en el cuál se las pudiera ordenar. La lucha existe ciertamente, en términos de competencia inter e intra instituciones por recursos siempre escasos, pero en la misma, antes que el valor de una contribución a un capital común de conocimientos, lo que prima es el recurso a inevitables formas de capital social institu-

43. Sin perjuicio de que también en esos países estos consensos se hayan ido erosionando, la crisis mundial de la sociología se agudiza en Argentina.

44. 0 por lo menos que se lo discuta: según Juan Piovani (2018), es notable el bajo nivel de citas de artículos, y especialmente de reciente publicación, en las producciones locales. 
cional que atentan contra las condiciones necesarias para que se pueda hablar de un campo científico-académico autónomo.

En efecto, la variedad de la oferta educativa y editorial disponible - en el país como en el extranjero - redunda en agentes que presentan una multitud de combinaciones de propiedades disciplinares, teóricas, metodológicas, estilísticas, etc., sin que haya realmente un capital en común que permita situarlos unos con respecto a otros en un espacio jerarquizado.

En la sociología argentina, Bourdieu ocupa un lugar importante, pero no dominante ${ }^{45}$, junto a otras orientaciones de lo más diversas. Es evidente que su figura no tiene el mismo valor que en Francia: en Argentina, sin excluir ocasionales disputas por el legado, las luchas son más atemperadas. En cuanto a la importancia de la obra de Bourdieu en el campo, hay quiénes, como Elguezábal, pueden argumentar su no relevancia para entender la Argentina $^{46}$. En el otro extremo, G. Vommaro llega a afirmar que "Bourdieu [...] se volvió una especie de sentido común: todos somos un poco bourdieusianos en Argentina, todos los que somos sociólogos" (VOMMARO, 2018).

Ni lo uno ni lo otro. Como se ha mostrado, hay un amplio abanico de investigaciones exitosas llevadas adelante en una perspectiva bourdieusiana, esto es, haciendo un uso creativo de sus conceptos y métodos. Asumiendo siempre algo de heterodoxia, es evidente que mismo entre los investiga- dores que he presentado hay grandes diferencias en el modo de asumir esa herencia. Y por cierto están también los indiferentes, así como los detractores: es un hecho que se puede practicar con éxito la sociología al margen de Bourdieu, y que muchos lo hacen en diversas maneras.

No hay tampoco un campo del bourdieusianismo: excepto en efectos puntuales en regiones muy localizadas del espacio, no hay una lucha por un capital bourdieusiano. Como lo expresaba G. Vommaro: podrán haber "estrategias más individuales de exportación-importación, de vínculos con Francia, pero eso no alcanza para hacer un campo" (VOMMARO, 2018).

De los principales colaboradores de Bourdieu, M. de Saint-Martin, J.-C. Combessie, L. J. Wacquant, y G. Mauger, han producido intervenciones en el espacio argentino. Pero ninguno de ellos lo ha hecho con la eficacia de Gisèle Sapiro. Los desarrollos recientes no han hecho más que confirmar lo que se vislumbraba como una hipótesis al final de mi artículo de 2008. Si hay una red que agrupa a buena parte de quienes encuentran en Bourdieu la inspiración para su trabajo, es sin duda la que ella ha venido urdiendo con constancia en los últimos años.

\section{Referencias}

ASSUSA, G. De la escuela al trabajo y del trabajo a la escuela. Una economía simbólica de la vida escolar, barrial y laboral de jóvenes de clases populares. Buenos Aires: Noveduc, 2018.

45. Empero, en las ponencias en congresos de sociólogos y antropólogos argentinos Bourdieu y Foucault suelen disputarse el primer lugar entre los autores referidos (BARANGER, 2011), muy por delante de todo el resto.

46. En Francia, "si se le pregunta a un bourdieusien por qué lo es, contesta que cuando vio el esquema de La distinción entendió todo. En Argentina ese esquema no dice casi nada”. 
ASSUSA, G. Jóvenes trabajadores, disputas sobre sentidos, apropiaciones simbólicas y distinciones sociales en el mundo laboral. Buenos Aires: GEU, 2017.

AUYERO, J. Faire patienter, c'est dominer: le pouvoir, l'État et l'attente. Actes de la Recherche en Sciences Sociales, n. 226-227, p. 120-125, 2019. http://doi.org/10.3917/arss.226.0120

AUYERO, J. L'espace des luttes. Topographie des mobilisations collectives. Actes de la Recherche en Sciences Sociales, v. 160, p. 122-132, 2005.

AUYERO, J.; BENZECRY, C. The Practical Logic of Political Domination. Conceptualizing the Clientelar Habitus. Sociological Theory, v. 35, n. 3, p. 179-199, 2017. https://doi. org/10.1177\%2F0735275117725767

BARANGER, D. Antropología social y sociología argentinas: identidades disciplinares en cuatro congresos. Revista Latinoamericana de Metodología de las Ciencias Sociales, v. 1, n. 2, p. 23-59, 2011.

BARANGER, D. La obra de Pierre Bourdieu y su recepción en Latinoamérica. In: DURÁN, A. M.; RAMÍREZ, J. E. (orgs.). Pierre Bourdieu. Proyección Siglo XXI. Bogotá: ILAE, 2013, p. 157-194.

BARANGER, D. The Reception of Bourdieu in Latin America and Argentina. Sociologica, n. 2, 2008. Disponible en: <https://www.academia. edu/3912699/The_Reception_of_Bourdieu_in_Latin_America_And_Argentina>. Acceso en: 11 out. 2019. http://doi.org/10.2383/27724

BEAUD, S.; PIALOUX, M. Repensar la condición obrera. Investigación en las fábricas de Peugeot de Sochaux- Monbéliard. Traducción de Antonia García Castro. Buenos Aires: Antropofagia, 2015.

BEIGEL, F. (org.). The politics of Academic Autonomy in Latin America. Londres: Ashgate, 2012.

BEIGEL, F. Científicos Periféricos, entre Ariel y Calibán. Saberes Institucionales y Circuitos de Consagración en Argentina. Las publicaciones de los Investigadores del CONICET. Dados, v. 60, n. 3, p. 825-865, 2017. http://dx.doi. org/10.1590/001152582017136
BEIGEL, F.; GALLARDO, 0.; BEKERMAN, F. Institutional expansion and scientific development in the periphery: the structural heterogeneity of Argentina's academic Field. Minerva, v. 56, n. 3, p. 305-331, 2018. https://doi.org/10.1007/s11024017-9340-2

BEKERMAN, F. La investigación científica argentina en Dictadura. Transferencias y desplazamientos de recursos (1974-1983). Mendoza: Ediunc, 2018.

BENZECRY, C. ¿Cómo Pez En El Agua? Aporías De La Sociología Disposicional. Cuestiones de Sociología, n. 16, p. e026, 2017. http://doi. org/10.24215/23468904e026

BENZECRY, C. El fanático de la ópera. Etnografía de una obsesión. Buenos Aires: Siglo XXI, 2011.

BENZECRY, C. The Opera Fanatic. Ethnography of an Obsession. Chicago: University of Chicago Press, 2011.

BLANCO, A. Entrevista a Juan José Saer. Punto de Vista, v. 18, n. 53, p. 37-42, 1995.

BLANCO, A. Razón y modernidad. Gino Germani y la sociología argentina. Buenos Aires: Siglo XXI, 2006.

BLANCO, A.; JACKSON, L. C. Sociología en el espejo. Bernal: Unqui, 2015.

BLANCO, A.; WILKIS, A. The Internationalization of Sociology in Argentina 1985-2015: Geographies and Trends. In: HEILBRON, J.; SORÁ, G.; BONCOURT, T. (orgs.). The Social and Human Sciences in Global Power Relations. Cham (Suiza): Palgrave Macmillan, 2018, p. 215-241.

BOCCARA, G. La interculturalidad como campo social. Cuadernos Interculturales, v. 10, n. 18, p. 11-30, 2012

BOURDIEU, P. Curso de sociología general 1. Conceptos fundamentales. Traducción de Martínez Kolodens. Buenos Aires: Siglo XXI, 2019.

BOURDIEU, P. El sentido práctico. Traducción de Ariel Dilon. Buenos Aires: Siglo XXI, 2007. 
BOURDIEU, P. La distinción. Criterio y bases sociales del gusto. Traducción de María del Carmen Ruiz de Elvira. Madrid: Taurus, 1988.

BOURDIEU, P. La distinction. Critique sociale du jugement. París: Minuit, 1979.

BOURDIEU, Pierre. La misère du monde. Paris: Seuil, 2013a.

BOURDIEU, P. La nobleza de Estado. Traducción de Alicia Gutiérrez. Buenos Aires: Siglo XXI, 2013b.

BOURDIEU, P. Las estrategias de la reproducción social. Traducción de Alicia Gutiérrez. Buenos Aires: Siglo XXI, 2011.

BOURDIEU, P. Meditaciones pascalianas. Traducción de Thomas Kauf. Barcelona: Anagrama, 2006.

BOURDIEU, P. Science de la science et réflexivité. París: Raisons d'agir, 2001.

BOURDIEU, P.; WACQUANT, L. J. Sobre las astucias de la razón imperialista. Apuntes de Investigación, n. 4, p. 9-22, 1999.

CANÊDO, L. The Ford Foundation and the Institutionalization of Political Science in Brazil. In: HEILBRON, J.; SORÁ, G.; BONCOURT, T. (orgs.). The Social and Human Sciences in Global Power Relations. Cham (Suiza): Palgrave MacMillan, 2018, p. 243-266.

CAPDEVIELLE, J. Procesos de urbanización, políticas públicas y generación de renta del suelo en la ciudad de Córdoba, Argentina. Revista de Direito da Cidade, v. 9, n. 1, p. 163-181, 2017. https://doi. org/10.12957/rdc.2017.26521

CHAMPAGNE, P. Faire l'opinion. Le nouveau jeu politiqe. París: Minuit, 1990.

CLEMENS, E. S. et al. Careers in Print: Books, Journals, and Scholarly Reputations. American Journal of Sociology, v. 101, n. 2, p. 433-494, 1995.

COMBES, H.; VOMMARO, G. Gouverner le vote des "pauvres". Champs experts et circulations de normes en Amérique Latine (regards croisés Argentine/Mexique). Actes de la Recherche en Sciences Sociales, n. 216-217, p. 4-23, 2017.
DEZALAY, Y.; GARTH, B. G. Sociología de la internacionalización. Villa María: Eduvim, 2017.

DUFY, C.; WEBER, F. Más allá de la gran división. Sociología, economía y etnografía. Traducción de Antonia García Castro. Buenos Aires: Antropofagia, 2009.

DUJOVNE, A. La máquina de traducir. Eudeba y la modernización de las ciencias sociales y humanas, 1958-1966. Papeles de Trabajo, v. 10, n. 18, p. 123-144, 2016.

DUJOVNE, A. Una historia del libro judío. La cultura judía argentina a través de sus editores, libreros, traductores, imprentas y bibliotecas. Buenos Aires: Siglo XXI, 2014.

DUKUEN, J. Habitus y dominación en la antropología de Pierre Bourdieu. Una crítica desde la fenomenología de Maurice Merleau-Ponty. Buenos Aires: Biblos, 2018a.

DUKUEN, J. Socialización política juvenil en un colegio de clases altas (Buenos Aires, Argentina). Revista Latinoamericana de Ciencias Sociales, Niñez y Juventud, v. 16, n. 2, p. 867-880, 2018c. https://doi.org/10.11600/1692715x.16215

ELGUEZÁBAL, E. Du luxe bon marché. Travail de service et classement social dans les résidences fermées de Buenos Aires. Actes de la Recherche en Sciences Sociales, n. 215, p. 38-55, 2016.

ELGUEZÁBAL, E. Fronteras urbanas. Los mundos sociales de las torres de Buenos Aires. Buenos Aires: Café de las Ciudades, 2018b.

ELGUEZÁBAL, E. La production des frontières urbaines: les mondes sociaux des "copropriétés fermées” à Buenos Aires. Tese (Doutorado) - Atelier National de Reproduction des Thèses, Lille, 2014a.

ELGUEZÁBAL, E. Que nul n'entre si... Les usages sociaux de la sécurité dans les "copropriétés fermées" de Buenos Aires. Actes de la Recherche en Sciences Sociales, n. 204, p. 10-23, 2014 b.

ELIAS, N. El proceso de civilización. Investigaciones sociogenáticas y psicogenéticas. Traducción de Ramón García Cotarelo. México: FCE, 1989. 
FLECK, C.; DULLER, M.; KARADY, V. Shaping Human Science Disciplines. Institutional Developments in Europe and Beyond. Londres: Palgrave MacMillan, 2019.

GAMBAROTTA, E. Bourdieu y lo político. Buenos Aires: Prometeo, 2018a.

GAMBAROTTA, E. El conflicto sobre el conflicto. Una instancia de los principios de visión y división de lo político, en la Ciudad Autónoma de Buenos Aires. Empiria Revista de Metodología de Ciencias Sociales, n. 39, p. 149-172, 2018b. https://doi. org/10.5944/empiria.39.2018.20881

GAMBAROTTA, E. Hacia una teoría crítica reflexiva. Max Horkheimer, Theodor W. Adorno y Pierre Bourdieu. Buenos Aires: Prometeo, 2014.

GUTIÉRREZ, A. La reproduction de la pauvreté. Note de recherche: Sur les échanges de capital social à Cordoba. Actes de la Recherche en Sciences Sociales, n. 160, p. 88-97, 2005.

GUTIÉRREZ, A. Las prácticas sociales. Una introducción a Pierre Bourdieu. Villa María: Eduvim, 2012.

GUTIÉRREZ, A. Pobre como siempre... Estrategias de reproducción social en la pobreza. Córdoba: Ferreyra Editor, 2004.

GUTIÉRREZ, A.; MANSILLA, H. O. Clases y reproducción social: el espacio social cordobés en la primera década del siglo XXI. Política y Sociedad, v. 52, n. 2, p. 409-441, 2015. http://dx.doi. org/10.5209/rev_POSO.2015.v52.n2.44467

HATHAZY, P. Cosmologías del Orden: Disciplina y Sacrificio en los Agentes Antidisturbios. Apuntes de Investigación del CECYP, v. 11, p. 45-63, 2006.

HATHAZY, P. C. Democratizing Leviathan: Bureaucrats, Experts and Politics in the Transformation of the Penal State in Argentina and Chile. Tesis (Doctoral) - Universidad de California, Berkeley, 2013.

HATHAZY, P.; FREDERIC, S. Presentación. Trabajo y Sociedad, v. 31, p. 5-13, 2018.
HEILBRON, J. Las ciencias sociales como un campo global emergente. Papeles de Trabajo, v. 10, n. 18, p. 21-48, 2016.

HEILBRON, J.; SORÁ, G. S.; BONCOURT, T. (orgs.). The Social and Human Sciences in Global Power Relations. Cham (Suiza): Palgrave/MacMillan, 2018.

HEREDIA, M. Cuando los economistas alcanzaron el poder (o cómo se gestó la confianza en los expertos). Buenos Aires: Siglo XXI, 2015.

HEREDIA, M. Redes contra campos. La unidad y la diversidad de los economistas en la Argentina reciente. Revista Latinoamericana de Estudios del Trabajo, n. 34, p. 59-90, 2016.

HEREDIA, M.; WILKIS, A. Introducción: la internacionalización de las Ciencias Sociales. Papeles de Trabajo, v. 10, p. 13-20, 2016.

HURTADO ARROBA, E. El oficio de la etnografía política Diálogo con Javier Auyero. ICONOS Revista de Ciencias Sociales, n. 22, p. 109-126, 2005. https://doi.org/10.17141/iconos.22.2005.87

JIMÉNEZ ZUNINO, C. Desclasamiento y reconversiones en las trayectorias de los migrantes argentinos de clases medias. Tesis (Doctoral) - Universidad Complutense, Madrid, 2013.

JIMÉNEZ ZUNINO, C. I. Transmisión intergeneracional y trayectorias sociales. Las clases medias cordobesas vinculadas a la industria automotriz. Trayectorias, México, v. 42, p. 3-27, 2016.

JURT, J. Naciones literarias: Una sociología histórica del campo literario. Traducción de Alejandro Dujovne. Villa María: Eduvim, 2014.

KAPLAN, C. La inteligencia escolarizada. Representaciones de los maestros sobre la inteligencia de los alumnos y su eficacia simbólica. Buenos Aires: Miño y Dávila, 2007.

KARSENTI, B. Marcel Mauss. El hecho social como totalidad. Traducción de Antonia García Castro. Buenos Aires: Antropofagia, 2008. 
LÓPEZ, M. P. La internacionalización de la investigación en las ciencias sociales. Una mirada sobre las prácticas internacionales de los historiadores. Papeles de Trabajo, v. 10, n. 18, p. 145-168, 2016.

MARTÍNEZ, A. T. Lectura y lectores de Bourdieu en Argentina. Prismas, v. 11, p. 11-30, 2007.

MARTÍNEZ, A. T. Pierre Bourdieu. Razones y lecciones de una práctica sociológica. Buenos Aires: Manantial, 2006.

MAUGER, G. La revuelta de los suburbios franceses: una sociología de la actualidad. Traducción de Antonia García Castro. Buenos Aires: Antropofagia, 2007.

MINCYT. (s.f.), Indicadores de Recursos Humanos en Investigación y Desarrollo (I+D), Hoja ract2_a.2.2. Disponible en: <https://back.argentina.gob.ar/indicadores-de-ciencia-tecnologia-einnovacion/recursos-humanos-en-id>. Acceso en: 15 dic. 2018.

MURMIS, M. Sociology, political science and anthropology: institutionalization, professionalization and internationalization in Argentina. Social Science Information, v. 44, n. 2-3, p. 227-282, 2005. https://doi.org/10.1177\%2F0539018405053290

NARDACCHIONE, G.; PIOVANI, J. I. Las sociologías post contemporáneas: discusiones teóricas, estrategias metodológicas y prácticas de investigación en contextos diferentes. Cuestiones de Sociología, n. 16, p. e023, 2017. https://doi. org/10.24215/23468904e023

NEIBURG, F.; PLOTKIN, M. Internationalisation et développement. Les "Di Tella" et la nouvelle économie en Argentine. Actes de la Recherche en Sciences Sociales, n. 151-152, p. 57-67, 2004.

NOEL, S. La edición independiente crítica: compromisos políticos e intelectuales. Traducción de Estela Consigli. Villa María: Eduvim, 2018.

OFFERLÉ, M. Perímetros de lo político: contribuciones a una socio-historia de la política. Traducción de Antonia García Castro. Buenos Aires: Antropofagia, 2011.
PIOVANI, J. I. Estilos de producción en el campo de las ciencias sociales en Argentina. Cuadernos de Información y Comunicación, v. 23, p. 125141, 2018. https://doi.org/10.5209/CIYC.60912

RUBINICH, L.; BELTRÁN, G. J. (orgs.). ¿Qué hacen los sociólogos? Buenos Aires: Aurelia Rivera, 2010.

SALATINO, M. Más allá de la indexación: circuitos de publicación de ciencias sociales en Argentina y Brasil. Dados, v. 61, n. 1, p. 255-287, 2018. http:// dx.doi.org/10.1590/001152582018152

SAPIRO, G. ¿Cómo las obras literarias atraviesan fronteras (o no)? Una aproximación sociológica a la literatura mundial. El Taco en la Brea, $n$. 7, p. 182-194, 2018a. https://doi.org/10.14409/ tb.v0i7.7363

SAPIRO, G. La guerre des écrivains: 1940-1953. París: Fayard, 1999.

SAPIR0, G. Pasajes: la teoría de los campos en sociología: génesis, elaboración, usos. El Taco en la Brea, v. 4, n. 5, p. 435-455, 2017.

SAPIRO, G. Los intelectuales: profesionalización, politización, internacionalización. Traducción de Alejandro Dujovne. Villa María: Eduvim, 2018b.

SAPIR0, G. Modelos de intervención política de los intelectuales. El caso francés. Traducción de Alejandro Dujovne. Prismas, v. 15, n. 2, p. 129153, 2011.

SORÁ, G. Editar desde la izquierda en América Latina. La agitada historia del Fondo de cultura económica y de Siglo XXI. Buenos Aires: Siglo XXI, 2017.

SORÁ, G. Francfort: la foire d'empoigne. Liber. Revue internationale des livres, v. 34, p. 2-3, 1998.

SORÁ, G. La maison et l'entreprise. José Olympio et l'évolution de l'édition brésilienne. Actes de la Recherche en Sciences Sociales, v. 126-127, p. 90-102, 1999.

SORÁ, G. Un échange dénié, La traduction d'auteurs brésiliens en Argentine. Actes de la Recherche en Sciences Sociales, v. 145, p. 61-70, 2002. http://dx.doi.org/10.3917/arss.145.0061 
SORÁ, G.; BLANCO, A. Unity and Fragmentation in the Social Sciences in Latin America. In: HEILBRON, J.; SORÁ, G.; BONCOURT, T. (orgs.). The Social and Human Sciences in Global Power Relations. Cham (Suiza): Palgrave MacMillan, 2018. p. 127-152.

SORÁ, G.; DUJOVNE, A. Translating Western Social and Human Sciences in Argentina: A Comparative Study of Translations from French, English, German, Italian and Portuguese. In: HEILBRON, J.; SORÁ, G.; BONCOURT, T. (orgs.). The Social and Human Sciences in Global Power Relations. Cham (Suiza): Palgrave MacMillan, 2018, p. 267-293.

VOMMARO, G.; COMBES, H. El clientelismo político. Desde 1950 hasta nuestros días. Traducción de Horacio Pons. Buenos Aires: Siglo XXI, 2016.

VOMMARO, G.; WILKIS, A. Por una lectura práctica. A propósito de Repensar la condición obrera. Sociología del Trabajo, v. 85, p. 93-105, 2015.

WILKIS, A. Las sospechas del dinero. Moral y economía en la vida popular. Buenos Aires: Paidós, 2013.

WILKIS, A. The Moral Power of Money. Morality and Economy in the Life of the Poor. Stanford: Stanford University Press, 2018b.

WILKIS, A.; GARRIGA, J. Prólogo al Dossier Idaes 20 años. Papeles de Trabajo, n. esp. 5, 2018.

\section{Lista de las entrevistas realizadas}

BEIGEL, F. Fernanda Beigel: entrevista. Entrevistador: Denis Baranger. Mendoza, 2018. m4a. 70 min. Skype.

BLANCO, A. Alejandro Blanco: entrevista. Entrevistador: Denis Baranger. Buenos Aires, 2018. m4a. 107 min.

DÍAZ, C. Carlos Díaz: entrevista. Entrevistador: Denis Baranger. Buenos Aires: Editorial Siglo XXI Argentina, 2018. m4a. $91 \mathrm{~min}$.

DUJOVNE, A. Alejandro Dujovne: entrevista. Entrevistador: Denis Baranger. Buenos Aires, 2018. m4a. 108 min. Skype.
DUKUEN, J. Juan Dukuen: entrevista. Entrevistador: Denis Baranger. Buenos Aires, 2018b. m4a. 106 min. Skype.

ELGUEZÁBAL, E. Eleonora Elguezábal: entrevista. Entrevistador: Denis Baranger. Dijon, 2018a. m4a. $84 \mathrm{~min}$. Skype.

GAMBAROTTA, E. Emiliano Gambarotta: entrevista. Entrevistador: Denis Baranger. Buenos Aires: Centro Cultural de la Cooperación, 2018c. m4a. 38 min.

GUTIÉRREZ, A. Alicia Gutiérrez: entrevista. Entrevistador: Denis Baranger. Córdoba, 2018. m4a. 93 min. Skype.

JIMÉNEZ ZUNINO, C. Cecilia Jiménez Zunino: entrevista. Entrevistador: Denis Baranger. Córdoba, 2018. m4a. 82 min. Skype.

RUBINICH, L. Lucas Rubinich: entrevista. Entrevistador: Denis Baranger. Buenos Aires: Universidad de Buenos Aires, 2008. wav. 83 min.

SORÁ, G. Gustavo Sorá: entrevista. Entrevistador: Denis Baranger. Córdoba, 2018. Word.

VOMMAR0, G. Gabriel Vommaro: entrevista. Entrevistador: Denis Baranger. Buenos Aires, 2018. m4a.84 min. Skype.

WILKIS, A. Ariel Wilkis: entrevista. Entrevistador: Denis Baranger. Buenos Aires: Café Havanna, 2018a. m4a. 88 min. 
RESUMO

Para abordar a recepção de Bourdieu na Argentina no século XXI, começamos descrevendo as condições socioeconômicas e institucionais que permitiram em grande parte deste período um desenvolvimento excepcional das ciências sociais em geral e, nesse contexto, o florescimento de obras de inspiração Bourdieusiana. Em seguida, apresentam-se as trajetórias de uma seleção de expoentes dessa tradição, com o objetivo de mostrar os diferentes caminhos que eles seguiram nos últimos anos. Finalmente, concluímos discutindo sobre o não-campo das ciências sociais na Argentina e sobre o lugar do Bourdieusianismo nesse espaço.

PALAVRAS-CHAVE

Recepção de Bourdieu na Argentina. Ciências Sociais. Trajetórias.

\section{ABSTRACT}

To address the reception of Bourdieu in Argentina in the 21st century, we begin by describing the socio-economic and institutional conditions that have allowed, throughout most of this period, an exceptional development of social sciences as a whole and, within this context, the flourishing of Bourdieusian-inspired works. Then, the trajectories of a selected set of exponents of this tradition are presented in order to show the different pathways they have undertaken in recent years. Finally, we conclude by discussing the non-field of social sciences in Argentina, and the place occupied by Bourdieusianism in that space.

\section{KEY-WORDS}

Reception of Bourdieu in Argentina. Social Sciences. Trajectories.

Recebido em: 27/12/2018

Aprovado em: 02/06/2019 
